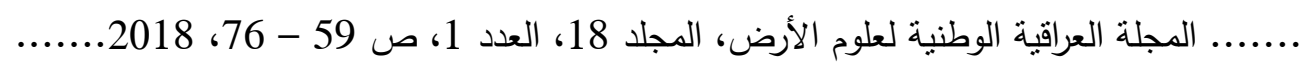

تحليل إنهيال المنحدرات في الجناح الجنويي الغزبي لطية بيرات المحدبة - شمال شرق العراق باستخدام الإسقاط الستريوغرافي

$$
\begin{aligned}
& \text { هدير غازي محمد أديب } \\
& \text { مركز بحوث السدود } \\
& \text { والموارد المائية } \\
& \text { جامعة الموصل } \\
& \text { ( تاريخ الاستلام 2013/6/24 تاريخ القبول 2014/1/16 ) }
\end{aligned}
$$

الملخص

تم دراسة استقرارية المنحدرات الصخرية على طريق عقرة - أربيل المجاور لقرية بخمة وعلى الجناح الجنوبي الغربي لطية بيرات المحدبة لبيان أخطار حركات الانهيال المتكررة هناك. تم اختيار سبعة محطات التهات

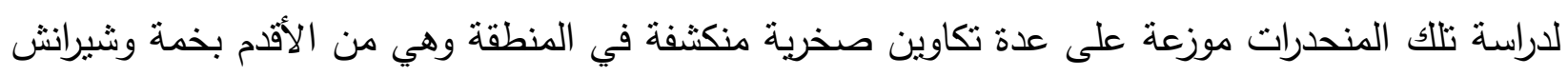

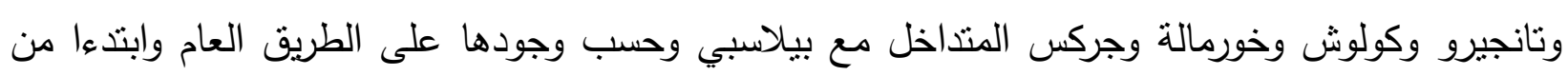
جسر بخمة الحديدي.

استخدمت تقنية الإسقاط الستيريوغرافي المجسم في تحليل وتصنيف المنحدرات الصخرية. يكون

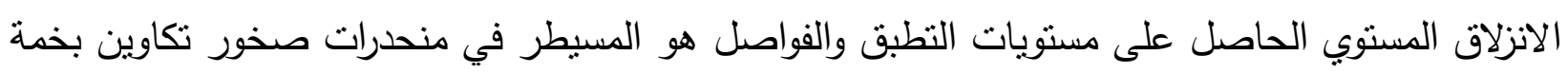
وشيرانش وبيلاسبي وفي بعض من منحدرات تكوين خورمالة. أما الطبيعة الصخارية لتكاوين تانجيرو

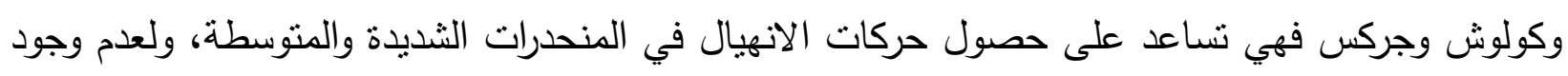

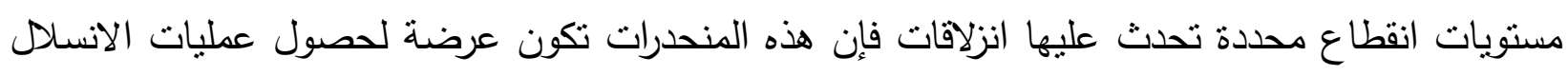
( Raveling ) تتأثر بعض المنحدرات الصخرية لتكوين خورمالة بالانزلاق الإسفيني بين سطح التطبق ومستويات الفواصل على امتداد خط تقاطعها مع ذلك السطح. الكلمات الدالة: استقرارية المنحدرات، الانزلاق، بخمة، الإسقاط الستنريوغرافي، بيرات.

\section{Analysis of Slope Failure at the Southwestern Limb of Perat Anticline - NE Iraq Using Stereographic Projection}

\author{
Hadeer Gh. M. Adeeb \\ Dams and Water \\ Resources Center \\ University of Mosul
}


Rock slopes analysis in south western limb of Perat anticline, near Bekhme village, were studied. Seven stations were chosen to study these slopes which distributed along several exposed formations of Bekhme, Shiranish, Tanjero, Kolosh, Khurmala, and Gercus interbeded with Pila Spi according to their existence on the road, beginning from the Iron Bridge of Bekhme.

Stereographic projection technique was used in analyzing and classifying these slopes. Plane sliding along bedding planes and joints is the predominant in the formations of Bekhme, Shiranish, Pila Spi and some of khurmala Formation. Clastic rock Formations of Tanjero, Kolosh, and Gercus help to failure in steep and moderate slopes. Because of no distinctive favorable discontinuities to slide along, these slopes are suffering from raveling processes which means granular disintegration into small components by different processes. The rock slopes of Khurmala Formation are affected by wedge sliding along discontinuities intersections with bedding planes.

Keywords: Slopes Stability, Sliding, Bekhme, Stereographic projection. Perat.

\section{المقدمة}

إن جزءاً من الطريق العام الموصل بين موقع سد بخمة واربيل مروراً بشقلاوة وصلاح الدين، يكون

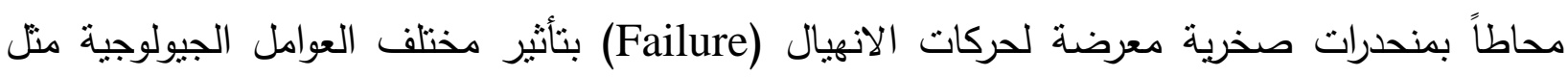
وضعية الطبقات والانقطاعات والعلاقة الهندية فيما بينها وبين وضعية المنحدر الصخري وكنلك الطبيعة الصخرية لمكانثفا، مما يعرض سالكي هذا الجزء من الطريق إلى مخاطر هذه الحركات بسبب المنحدرات الصخرية.

تثنمل منطقة الدراسة المنحدرات الصخرية المحيطة بجزء الطريق الواقع عند الجناح الجنوبي الغربي لطية

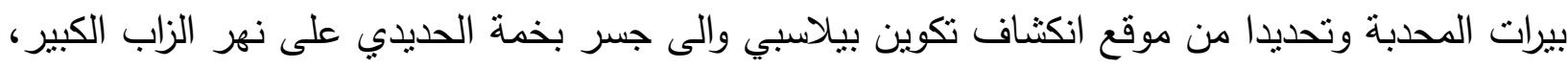

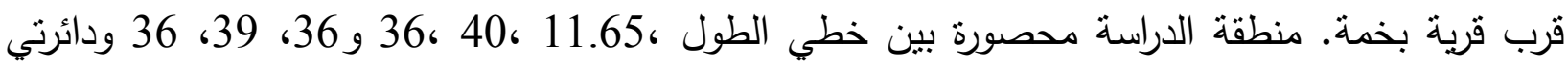

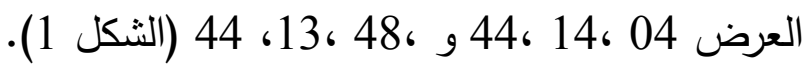

وتبعد المنطقة بحدود (160) كم عن مدينة الموصل و (60) كم عن قضاء عقرة وباتجاه محافظة

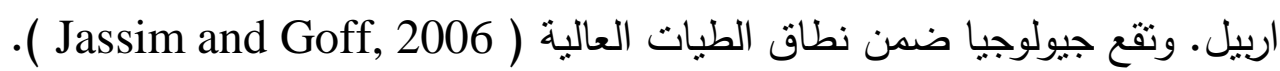
تهدف الدراسة إلى تحليل اسنقرارية المنحدرات الصخرية لكل من تكوينات بخمة، شيرانش، تانجيرو، ، كولوش، وجركس مع بيلاسبي المنداخلين في الجناح الجنوبي الغربي للطية. وكذللك تحديد أنواع حركات الانهيال الحاصلة والمحتملة بوصفها من المظاهر الطبيعية الثائعة والمتكررة الحدوث في مناطق الطيات العالية. وتقيد هذه الدراسة في وضع تصاميم الطرق والجسور والمنشآت الخدمية في هذه المنطقة. 


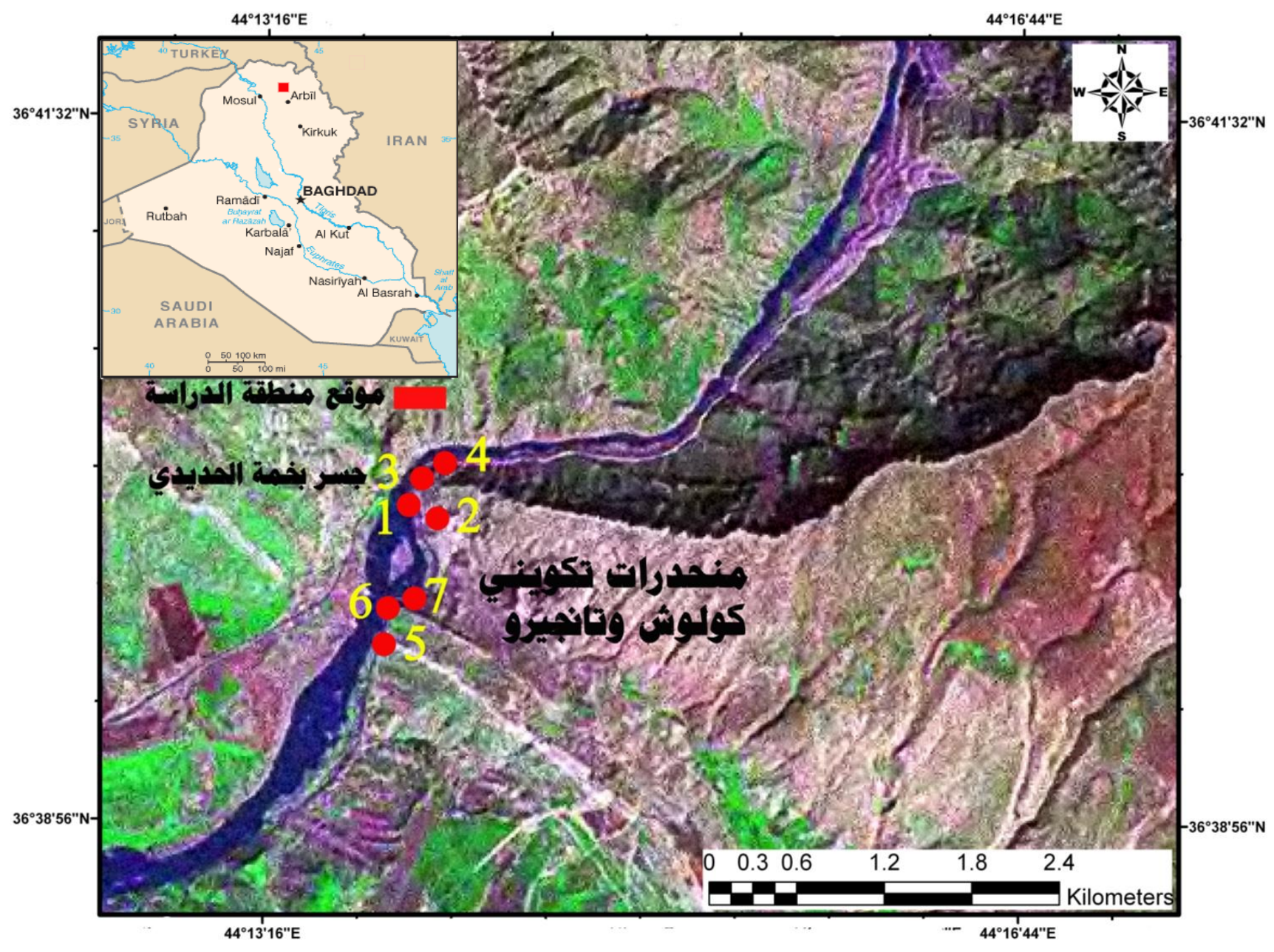

الثكل 1: مرئية فضائية مأخوذة من القمر الاصطناعي لاندسات لموقع منطقة الدراسة مبينا عليها مواقع المحطات.

\section{طرائث البحث}

أنجز البحث من خلال محورين أساسيين؛ هما العمل الحقلي والعمل المكتبي. في الأول تم القيام بمسح تقصيلي لثكل المنحدرات الهندسي وطبقاتها الصخرية، وكذلك خصائص الانقطاعات فيها. اختيرت سبع محطات للاراسة على أساس تكرارية حدوث حركات الانهيال أو (Discontinuities ) احتمال حدوثها. وفي كل من هذه المحطات أخذت قياسات الوضعية لوجه المنحدر ومستويات التطبق والفواصل بصيغة زاوية الميل/ اتجاه الميل. ومن ثم تصويرها حقليا. في الثاني، تم تمثيل البيانات المجمعة قياساتها باستخدام تقنية الإسقاط الستيريوغرافي لغرض تعبين نوع وطبيعة حركة الانهيال الحاصلة أو المحتملة الحدوث في المحطة المدروسة. تم الاستعانة بالبرنامج الحاسوبي (GEORIENT ( 9.2) لإجراء تحليلات الإسقاط الستيريوغرافي. استخدمت قيم زاوية الاحتكاك الداخلي Ø للصخور في منطقة الدراسة والمستتنجة من قبل (Al- Jawadi, 2013) وتمثيلها في مخططات الإسقاط الستيريوغرافي. 
واستخدمت الرموز والألوان الآتية لتمثيل البيانات:

Ø: زاوية الاحتكاك الداخلي لأسطح الانقطاع بدائرة صغرى باللون الأسود. Gs S : S : S Sج: S S S

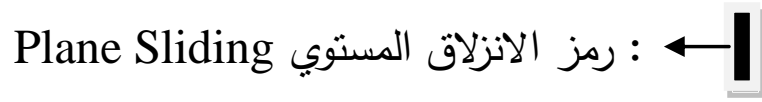

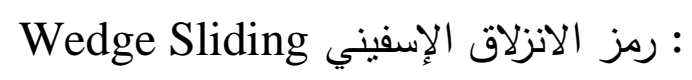
Rock Fall رمز السقوط الصخري الائلاقي : رمز

\section{جيولوجية منطقة الاراسة}

إن طية بيرات المحدبة هي احدى تراكيب نطاق الطيات العالية في شمال شرق العراق المحاذية لنطاق

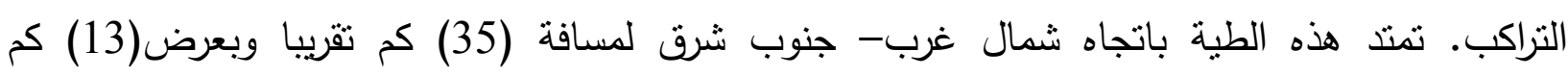

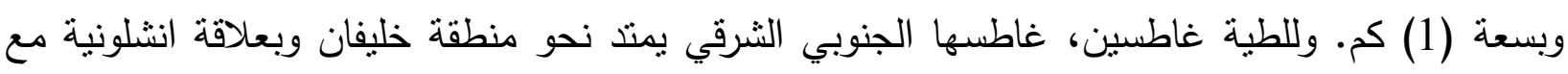

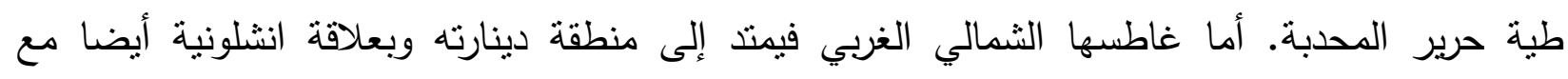
الغاطس الثرقي لطية عقرة.

وصف الحمداني (الحمداني، 1991 ) التتابع الطباقي الصخري المنكثف في طية بيرات، ( الجدول 1). يتضمن التركيب الصخري لهذه التتابعات بشكل عام تتاوب من طبقات جيرية ودولومايتية

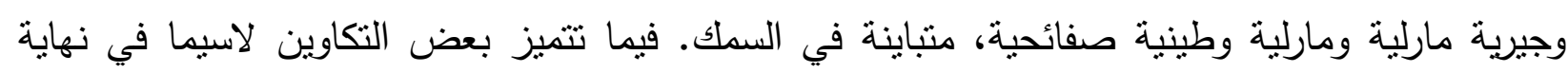

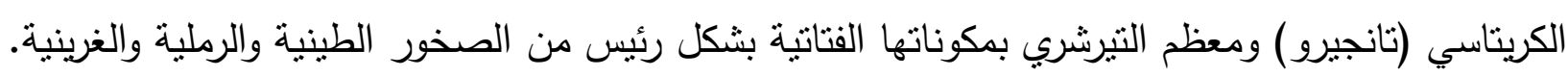
و(الثكل 2) يوضح الخارطة الجيولوجية لمنطقة الدراسة (Omer, 2005). 
الجدول 1: التتابع الطباقي لطية بيرات المحدبة، (الحمداني، 1991).

\begin{tabular}{|c|c|c|c|}
\hline الوصف الطباقي & العمر & السمك/متر & 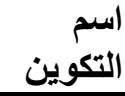 \\
\hline حجر طيني وصلصالي ورملي وسلتي & المايوسين الاعلى & 150-350 & 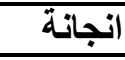 \\
\hline الجبس طيني الطرف الجنوبي الفربية لطية بيرات المحدبة ، عدسات من & المايوسين الاوسط & $180-200$ & 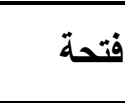 \\
\hline حجر جيري دولومايتي صلب جداً ومنطبق & الايوسين الاوسط_الاعلى & 30-50 & بيلاسبي \\
\hline الكلعبق طبقات من الحجر الجيري والرملي والصلصال والسجيل & الايوسين الاوسط & 100-150 & 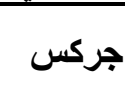 \\
\hline جيري صلصالي جيد التطبق & الالبوسيوسين الاسفل الاعلى & $90-140$ & خورمالة \\
\hline والرملي مع وجتئة رصداصية المدملكات غامقة من السجيل والحجر الطيني & الأبليوسين - الايوسين & $90-100$ & كولوش \\
\hline حجر رملي مع صلصال مع تواجد علسات من المدملكات & الماسترختيان الاسفل & $200-450$ & تانجيرو \\
\hline حجر جيري و حجر صلصالي & الماسترختيان - الكامبانيان & 190 & شيرانش \\
\hline 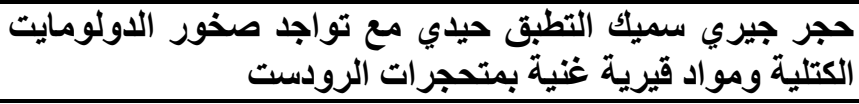 & الكامباتيان & 320 & 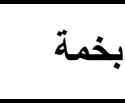 \\
\hline حجر رملي صلصي و حجر جيري متلألمت مع وجود طبقات رقيقة من & الهاتروفيان - الالبيان & 645 & قمجوقة \\
\hline طبقات ريزيقة من السلجيل و حجر جيري ذات تطبق جيا ومتعاقبة مع & الفالانجيان & 110 & 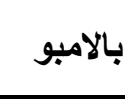 \\
\hline الصاقبات جيدة التطبق من الحجر الجيري و الحجر الجيري & البيريسيان & 150 & جياكارا \\
\hline
\end{tabular}

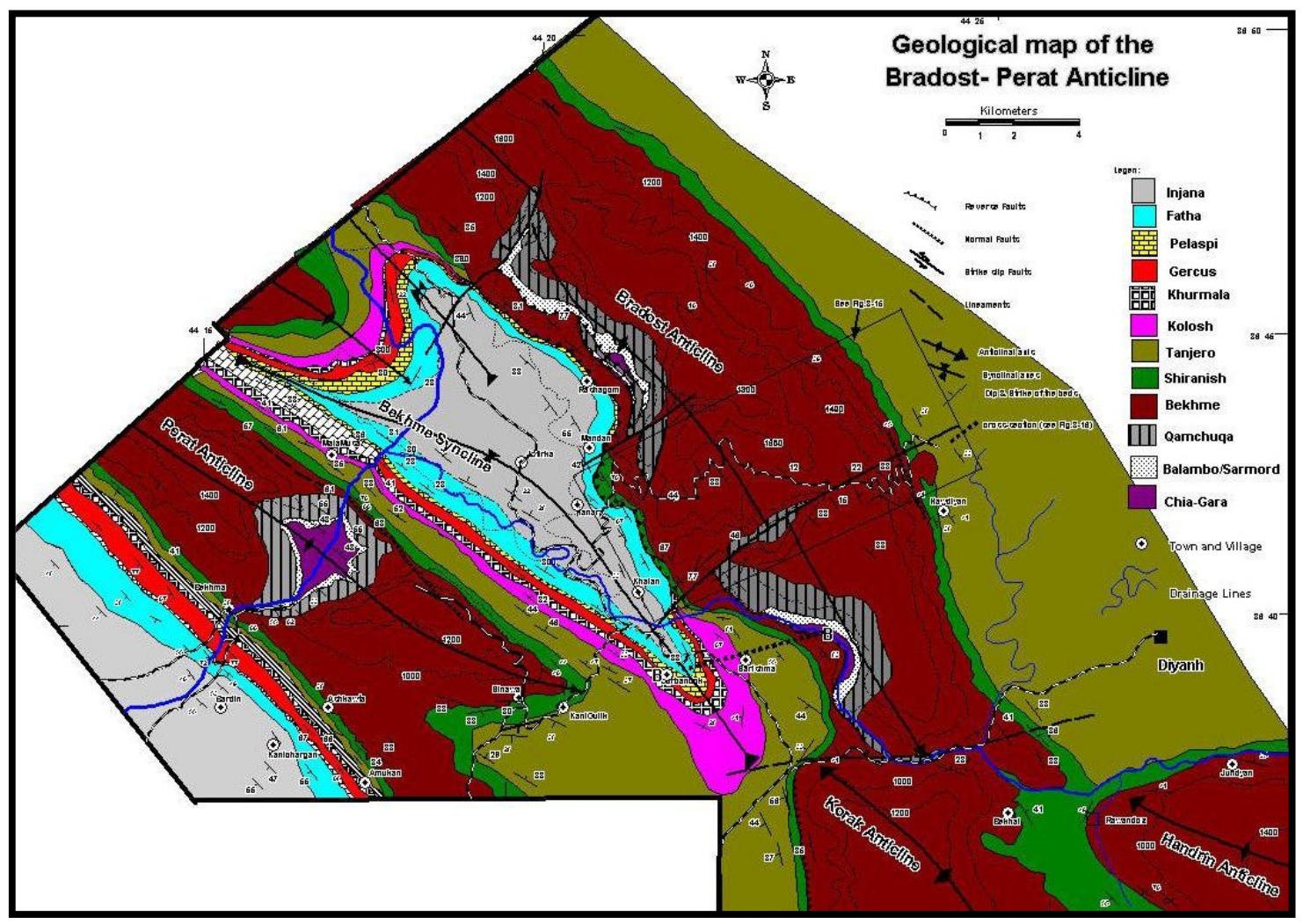

الثكل 2: الخارطة الجيولوجية لموقع منطقة الدراسة، (Omar, 2005). 
تحليل إستقرارية المنحدرات الصخرية لمنطقة الدراسة

تمت دراسة المنحدرات الصخرية لغرض تحليل إستقراريتها حسب المحطات المختارة في التكوينات

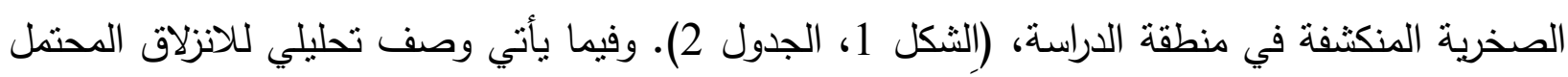

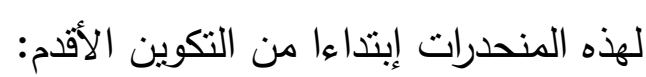

الجدول 2: المعاملات الجيولوجية والهندسية لمحطات منطقة الدراسة.

\begin{tabular}{|c|c|c|c|c|c|c|c|}
\hline \multicolumn{6}{|c|}{ المعاملات الجيولوجية والهندسية } & \multirow[b]{2}{*}{ التكوين } & \multirow[b]{2}{*}{ المحطة } \\
\hline 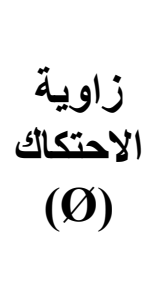 & ألانقطاع & الانقطاع & $\begin{array}{l}\text { ألانططاع } \\
\text { الأولىى } \\
\text { (S1) }\end{array}$ & سطح الانحدار (Gs) & التطبق & & \\
\hline 24 & $330 / 63$ & $027 / 56$ & $100 / 51$ & $250 / 70$ & $223 / 54$ & شير انش & 1 \\
\hline 24 & $320 / 63$ & $064 / 30$ & $117 / 86$ & $250 / 65$ & $216 / 51$ & شير انش & 2 \\
\hline 24 & $326 / 61$ & $315 / 80$ & $090 / 50$ & $270 / 86$ & $214 / 50$ & شير انش & 3 \\
\hline 50 & $030 / 80$ & $278 / 88$ & $033 / 51$ & $240 / 65$ & $224 / 58$ & بخمة & 4 \\
\hline 24 & $052 / 44$ & $270 / 24$ & $293 / 80$ & $290 / 80$ & $299 / 90$ & بيلاسبي & 5 \\
\hline 24 & $025 / 87$ & $194 / 34$ & $194 / 72$ & $220 / 60$ & 195/82 & 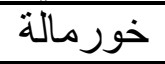 & 6 \\
\hline 24 & $120 / 42$ & $308 / 53$ & $310 / 81$ & $260 / 70$ & $195 / 82$ & 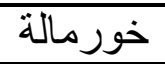 & 7 \\
\hline
\end{tabular}

1- 1 منحدرات صخور تكوين بخمة:

تطل هذه المنحدرات على الجانب الأيمن للطريق المؤدي إلى موقع سد بخمة. أجري تحليل الاستقرارية

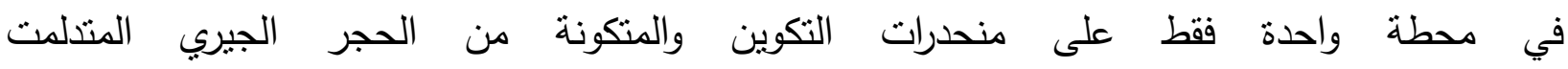
(محطة 4)، (الثكل 1). تتميز هذه المحطة باحتمالية حصول الانزلاق المستوي على مستويات التطبق

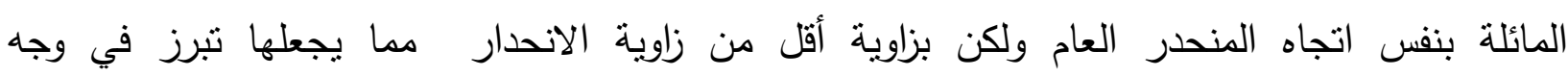

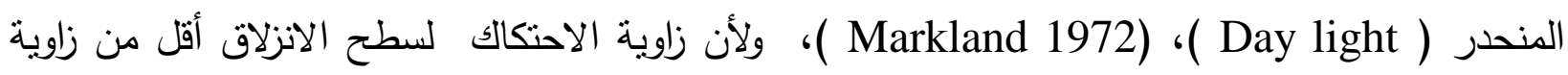

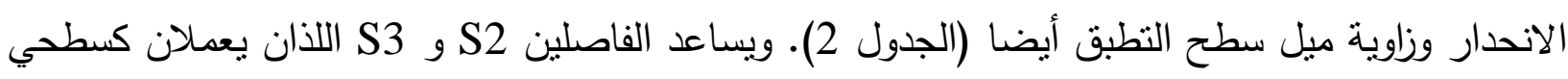
انطلاق جانبي (Lateral Release) وخلفي (Back Release) على التوالي على حدوث عملية الانزلاق 


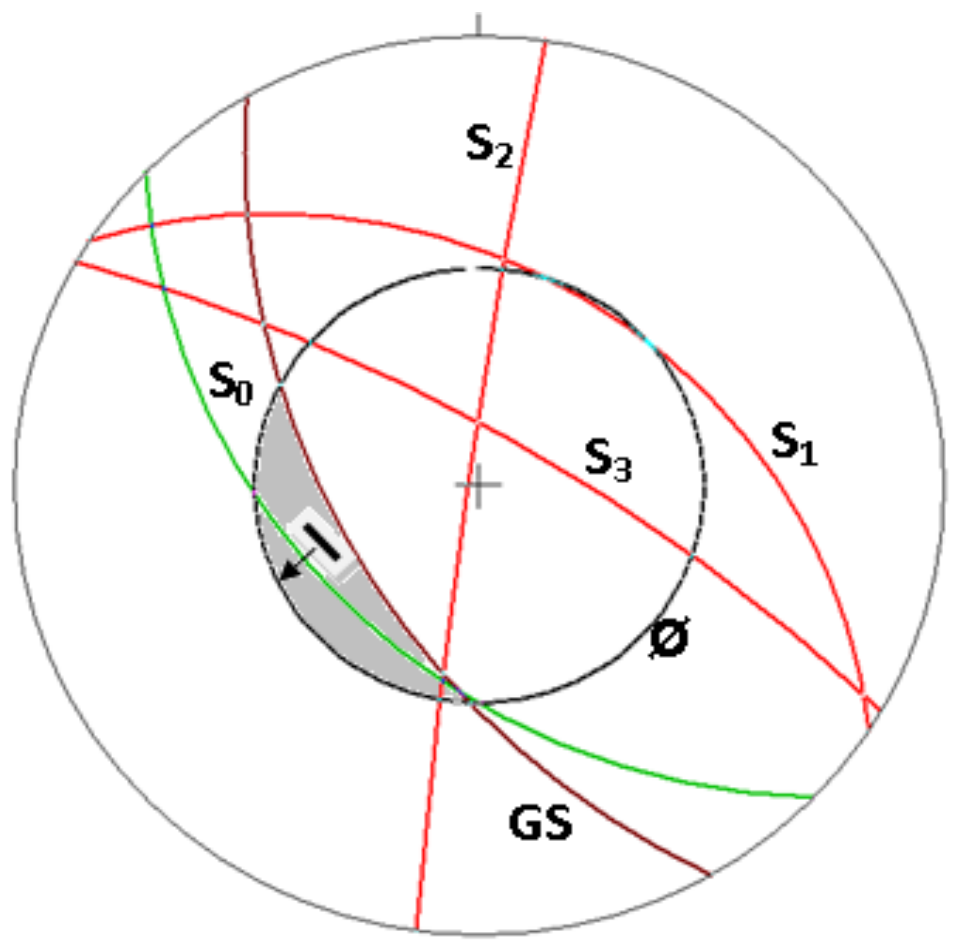

الثكل 3: المخطط الستيريوغرافي للمحطة (4) يبين العلاقة بين وجه المنحدر والانقطاعات المختلفة والانزلاق المستوي الحاصل على طبقات الحجر الجيري المتدلمت لتكوين بخمة.

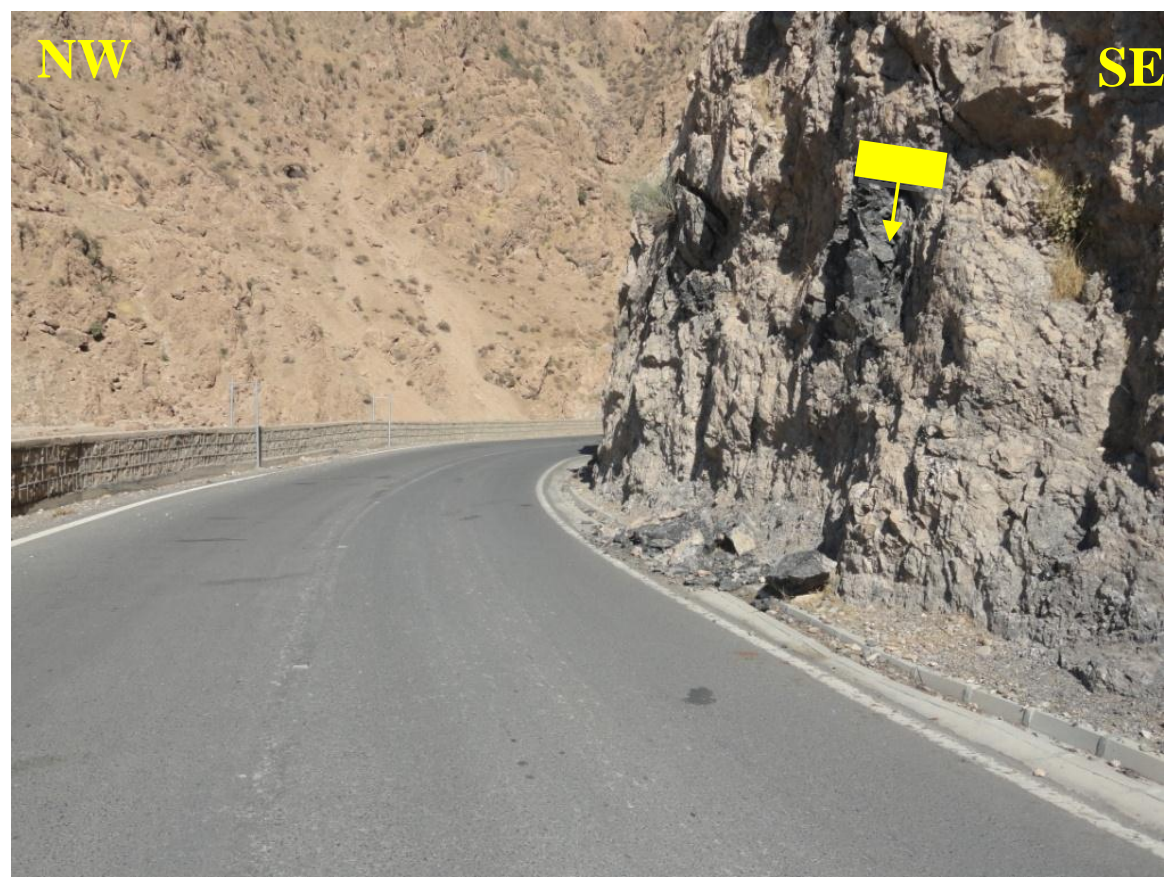

اللوحة 1: تبين الانزلاق المستوي على سطح النطبق بالنسبة لمنحدر الميل (Dip Slope) والساقط الصخري على الوجه الجانبي الثنديد الانحدار في المحطة (4 ) تكوين بخمة. 
2- منحدرات صخور تكوين شيرانش:

تحتل المنحدرات الصخرية لتكوين شيرانش والمنكونة من الحجر الجيري المارلي والمارل، (المحطتين 1 و 2 ) للجانب الثرقي من الطريق المؤدي إلى شقلاوة - أربيل، فيما تقع المحطة (3 ) على الجانب الأيمن من الطريق الفرعي المؤدي إلى موقع سد بخمة، (الثكل 1). وتتميز كل من هذه المحطات التثاثة بحصول الانزلاق المستوي على مستويات التطبق التي تبرز في وجه المنحدر وبسبب كون زاوية الاحتكاك لأسطح الانزلاق أقل من زاوية المنحدر العام. ويساعد الفاصلين S1 و S3 اللذان بعملان كسطحي انطلاق جانبي والفاصل S2 الذي يعمل كسطح انطلاق خلفي على حدوث عملية الانزلاق في المحطة (1)، (الثكل 4، اللوحة 2).

وفي المحطة (2) فإن الفاصلين 3S.S1 يساعدان على حصول الانزلاق كسطحي تحرر جانبيين، فيما يعمل الفاصل S2 كسطح تحرر خلفي (الثكل 5، اللوحة 3). بينما تعمل الفواصل S1 و S2 و S3 كأسطح تحرر جانبية في المحطة (3)، (الثكل 6، اللوحة 4).

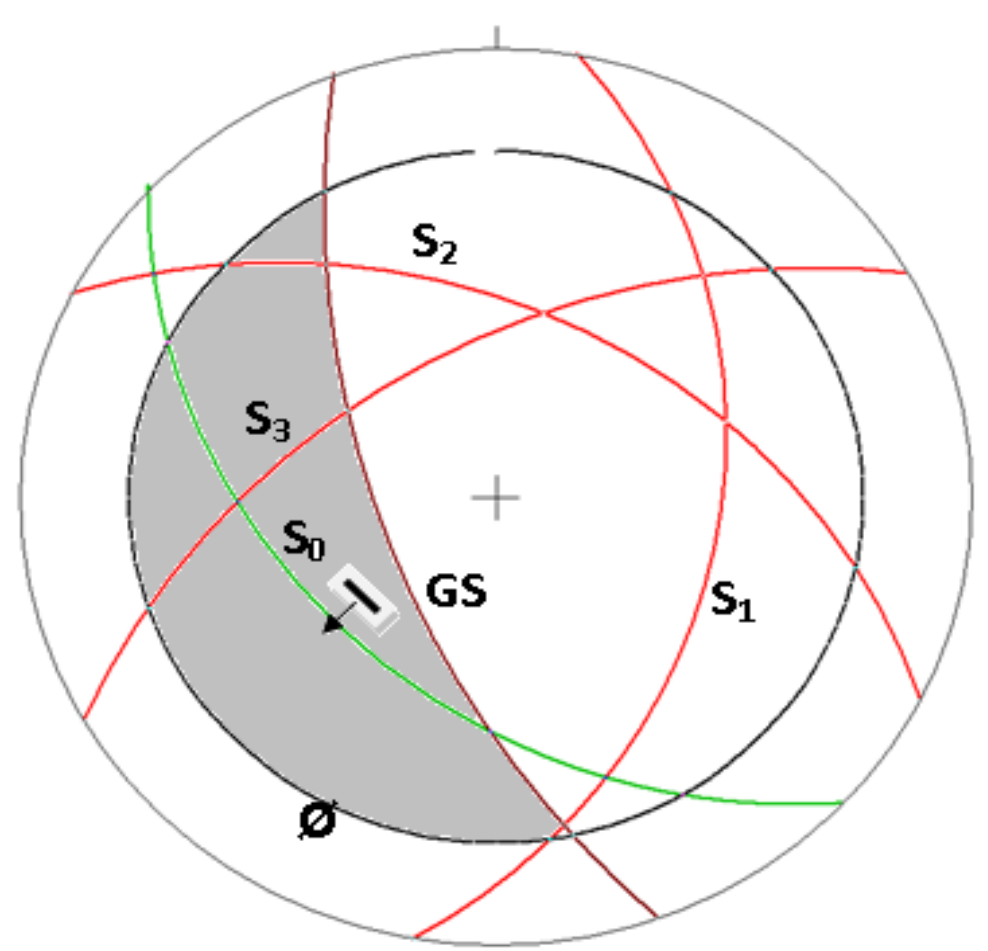

الثكل 4: المخطط الستيريوغرافي للمحطة (1) يبين العلاقة بين وجه المنحدر والانقطاعات المختلفة والانزلاق المستوي الحاصل على طبقات الحجر الجيري المارلي لتكوين شيرانش. 


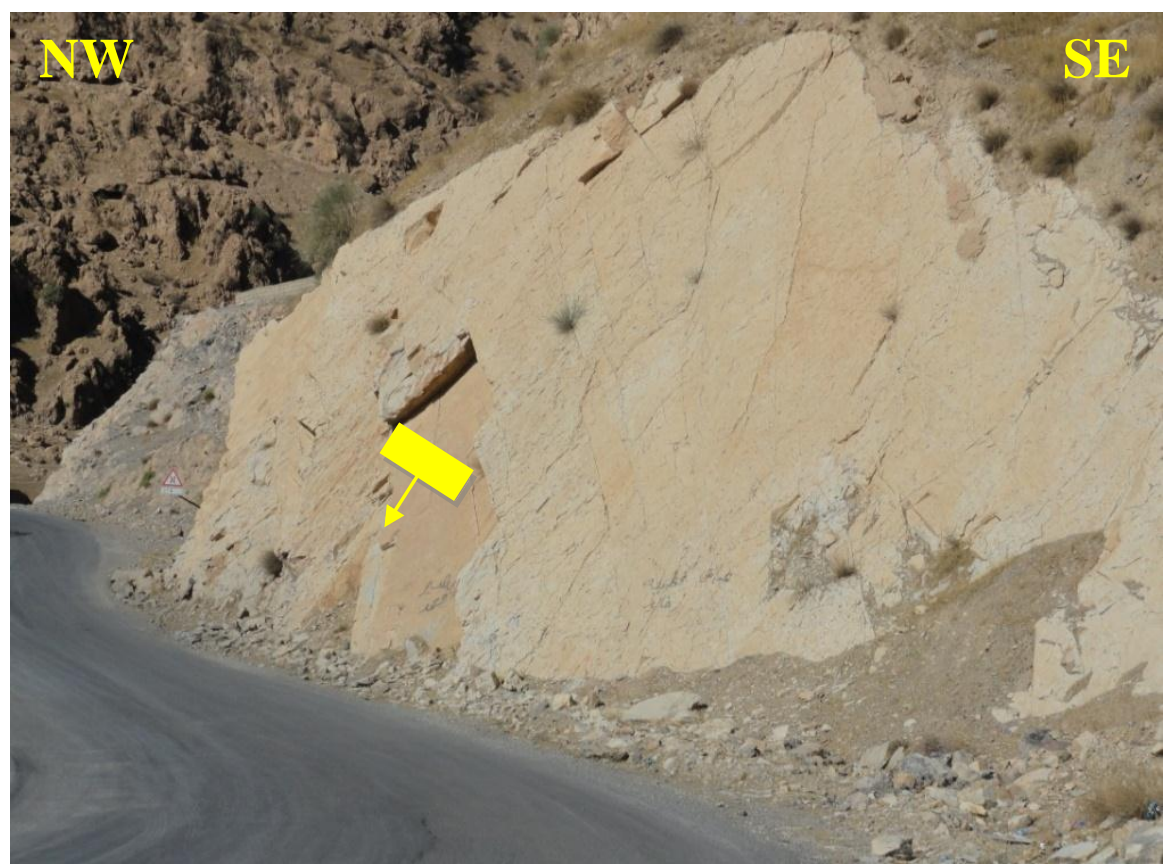

اللوحة 2: الانزلاق المستوي على طبقات الحجر الجيري المارلي لتكوين شيرانش ويلاحظ أثر الفواصل كأسطح تحرر جانبي وخلفي في المحطة (1).

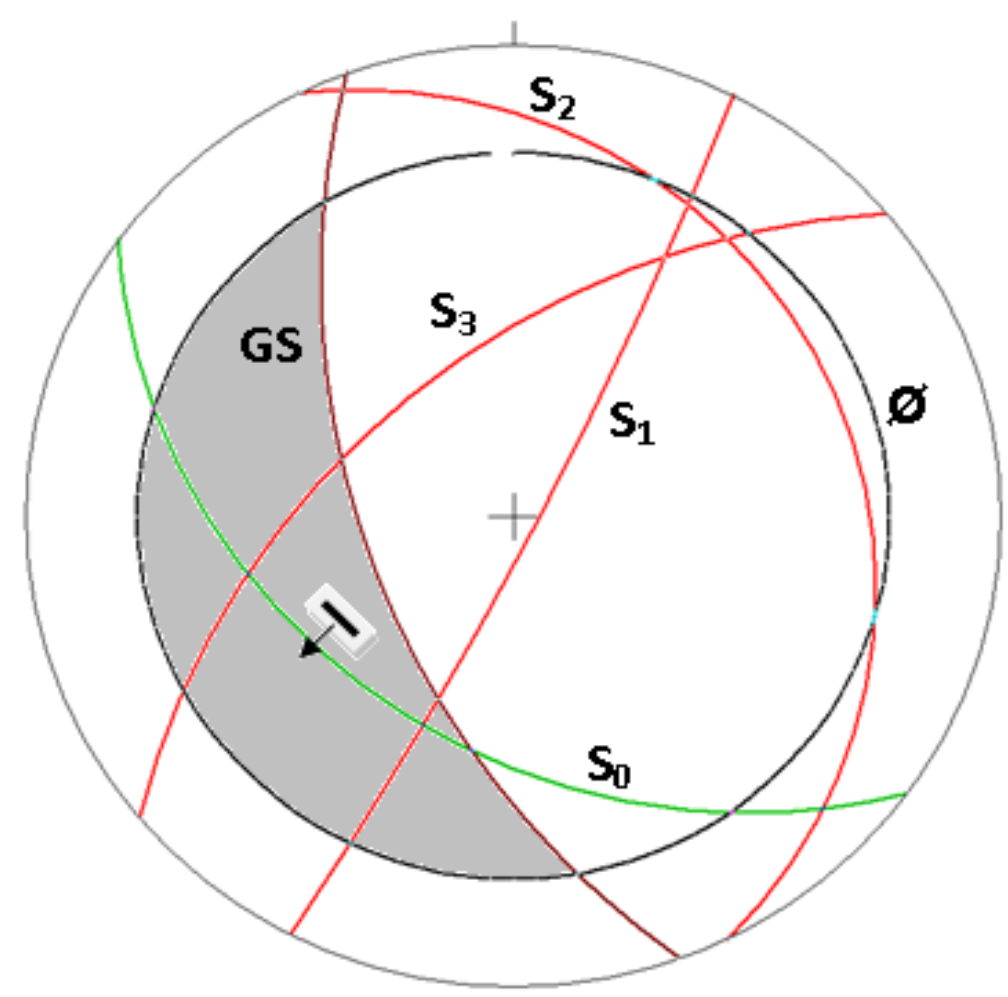

الثكل 5: المخطط الستيريوغرافي للمحطة (2) يبين العلاقة بين وجه المنحدر والانقطاعات الدختلفة والانزلاق المستوي الحاصل على طبقات الحجر الجيري المارلي لتكوين شيرانش. 


$$
\text { هدير غازي محمد أديب }
$$

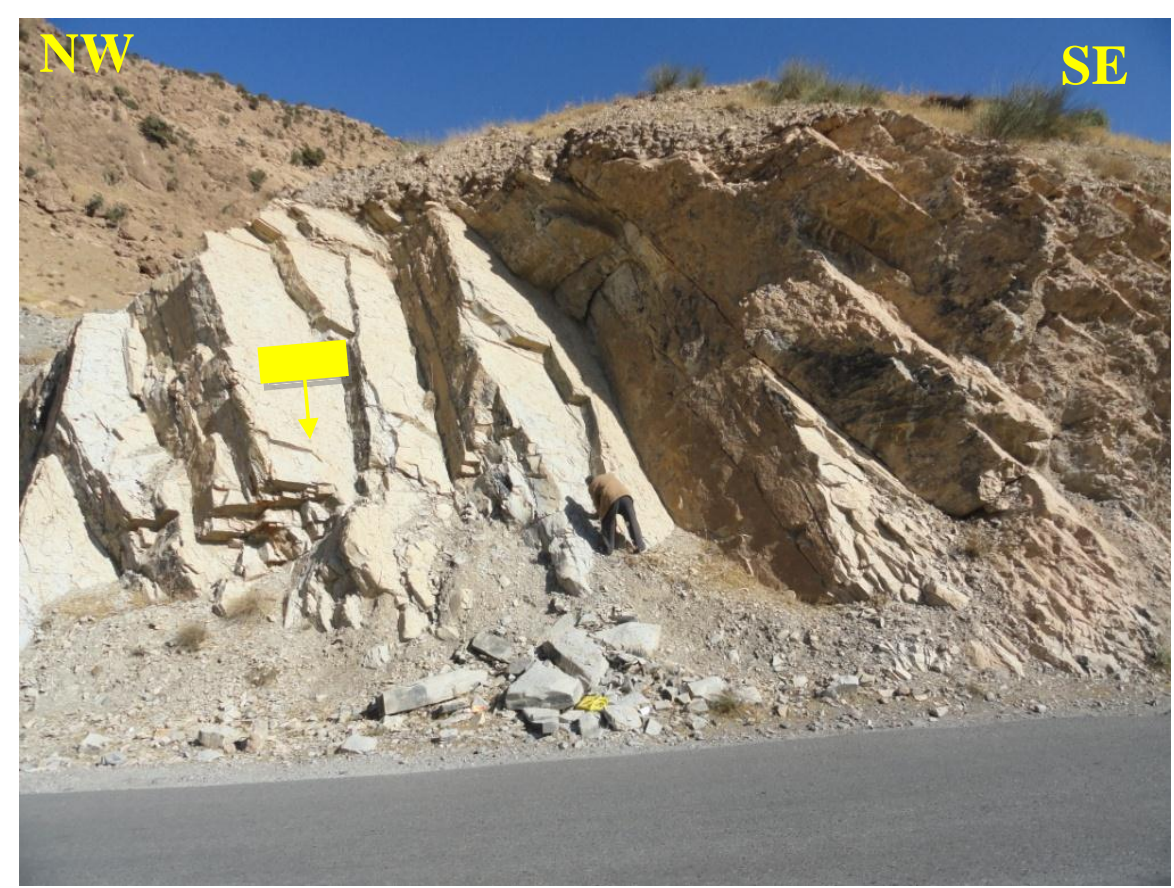

اللوحة 3: الانزلاق المستوي على طبقات الحجر الجيري المارلي لتكوين شيرانش ويلاحظ

أثز الفواصل كأسطح تحرر جانبي وخلفي في المحطة (2).

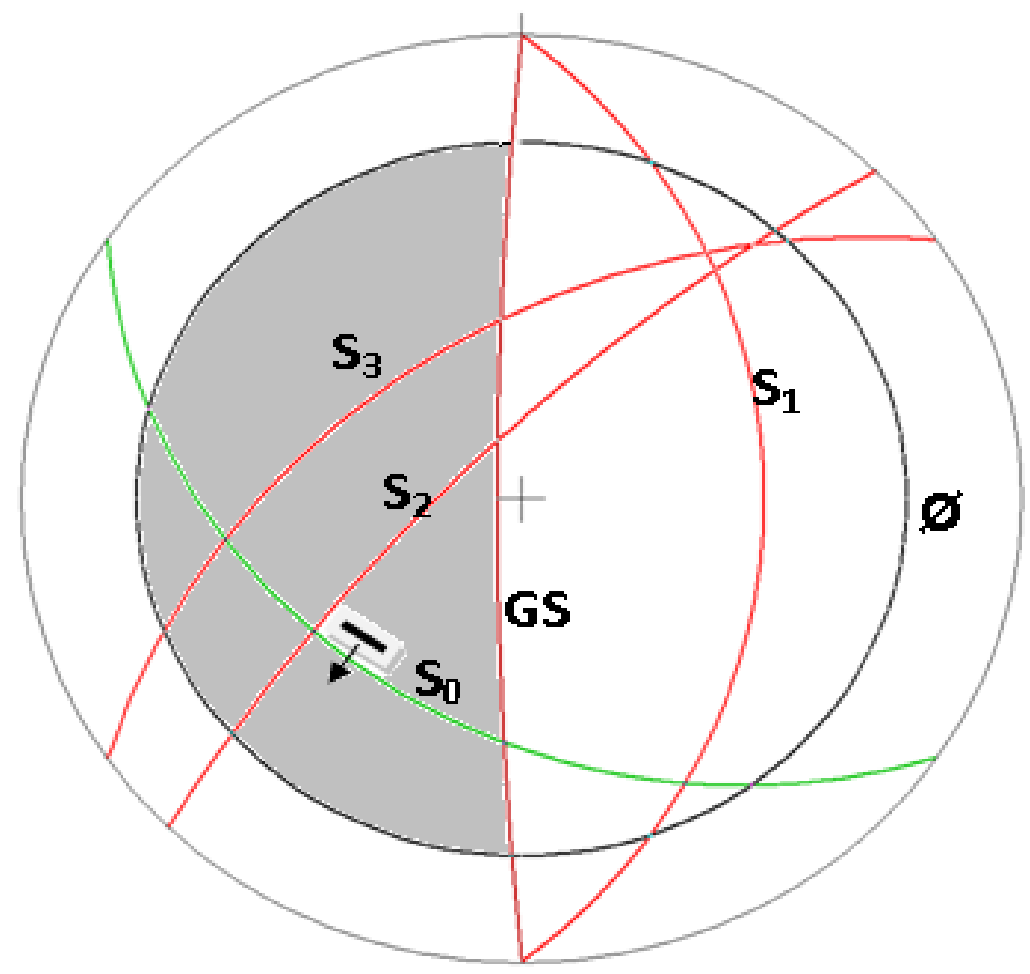

الثكل 6: المخطط السنتيوغرافي للمحطة (3) يبين العلاقة بين وجه المنحدر والانقطاعات المختلفة والانزلاق المستوي الحاصل على طبقات الحجر الجيري المارلي لتكوين شيرانش. 


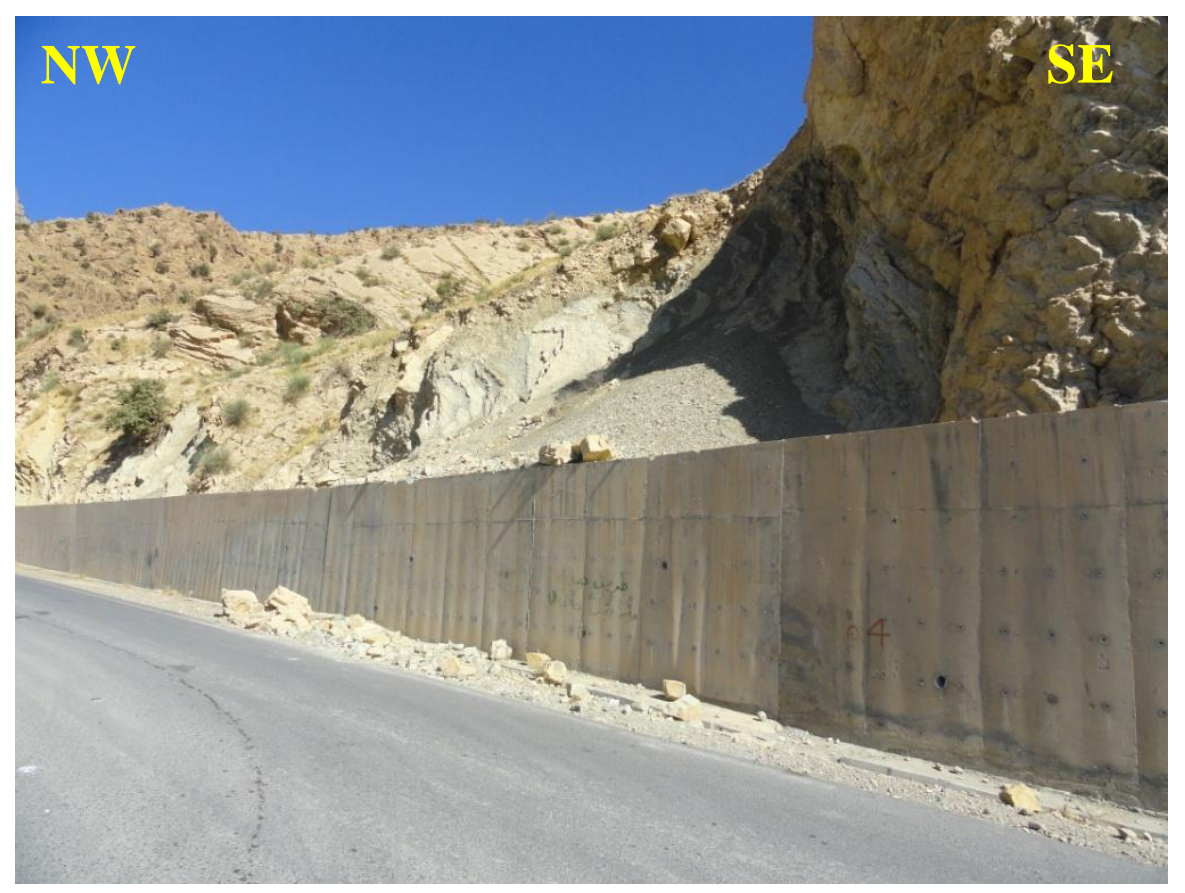

اللوحة 4: الانزلاق المستوي على طبقات الحجر الجيري المارلي لتكوين شيرانش في المحطة (4)، وكذلك يلاحظ تفتت طبقة المارل المتداخلة وانسلالها عبر الجدار الساند.

\section{3- المنحدرات الصخرية لتكويني تانجيرو وكولوش:}

تتشابه إلى حد ما الخصائص الصخارية والهندية لتكويني تانجيرو وكولوش، وبالتالي فان تصرفها يكون مشابها للعوامل الجيولوجية الهندسية المؤثرة وعليه فقد اعتبرا كوحدة جيولوجية هندسية واحدة. تتكثف ترسبات هذين التكوينين مباشرة على الجانب الثرقي من الطريق المؤدي إلى شقلاوة - صلاح الدين - أربيل.

إن الطبيعة الصخارية لهذين التكوينين تناعد على حصول حركات الانهيال وخاصة في المنحدرات الثديدة، ولكون إنحدارات هذين التكوينين في منطقة الدراسة واطئة نسبيا، ولعدم وجود مستوبات انقطاع محددة تحدث عليها انزلاق، فضلا عن أن مضرب طبقاتها تكون بزاوية عالية مع امتداد الطريق الرئيسي، لذا يستبعد احتمال حصول حركات الانهيال فيها. إلا إن هذه المنحدرات عرضة لحصول ما يسمى بعمليات الإنسال (Raveling) (Maerz, 2000) والتي هي عبارة عن عمليات التقتت الحبيبي للصخور الضعيفة عندما تتخلل المياه إلى داخل المسامات فتقلل من قوة تماسكه ومن ثم تفتيته وتحطيمه، فضلا عن عمليات الانجماد والتجفيف والترطيب المستمرة والتي تؤدي إلى تكوين قوى شدَية داخل الصخور تعمل على تفتيتها (Carson and Kirkby, 1972). إن تحطم صخور هذين التكوينين إلى قطع صخرية صغيرة تثحرج 
إلى أسفل المنحدر قد تثكل مخاطر جدية لكونها قريبة نسبيا من كتق الطريق الرئيسي مما يتطلب إنشاء جدار ساند للطريق وعلى طول هذا المنحدر (اللوحة 5 ).

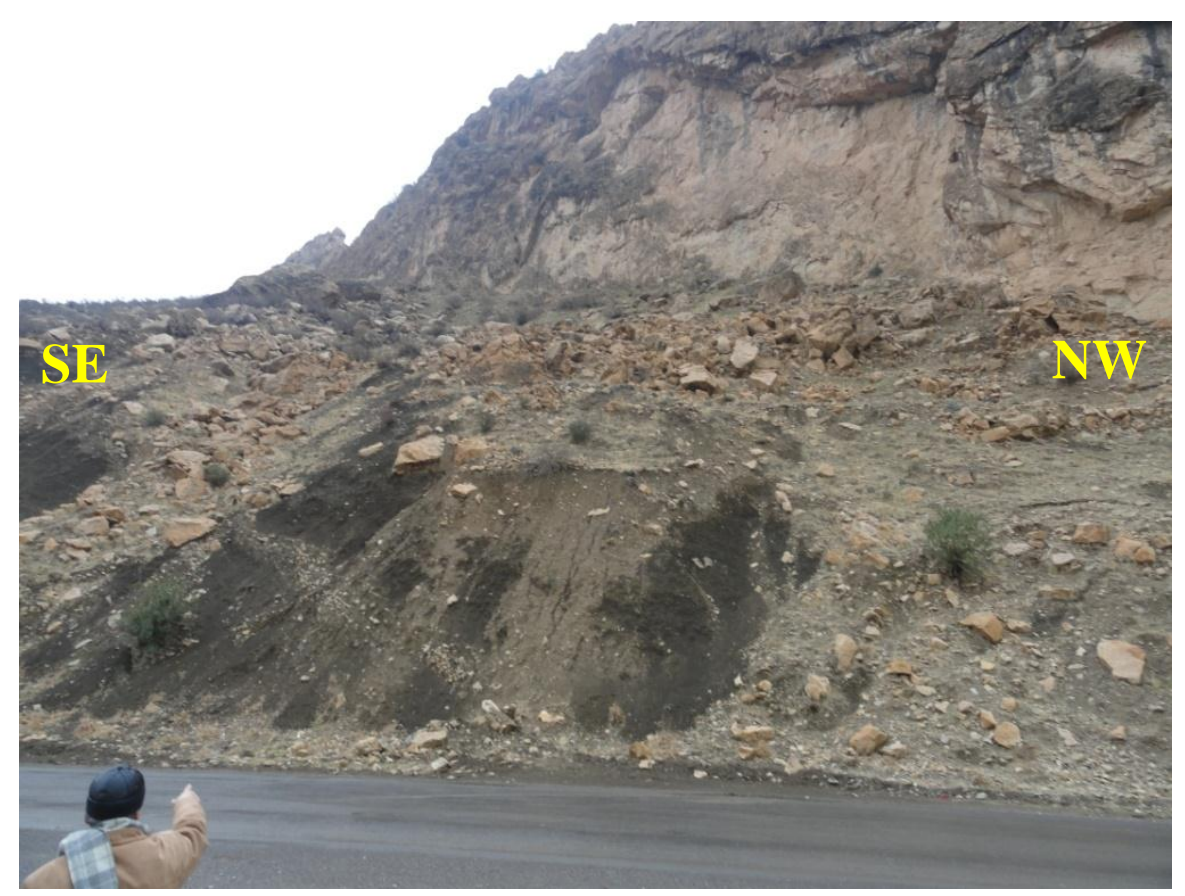

اللوحة 5: انسلال فتاتيات تكوين كولوش متجاوزة كتق الطريق.

4- المنحرات الصخرية لتكوين خورمالة:

تتكل صخور تكوين خورمالة، المتكونة من طبقات جيرية متذلمتة متتاوبة مع طبقات جيرية

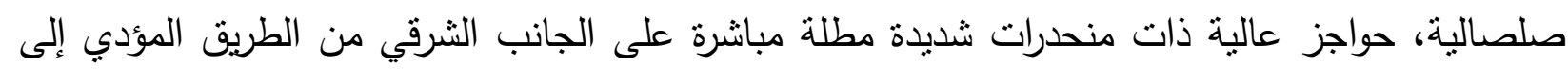

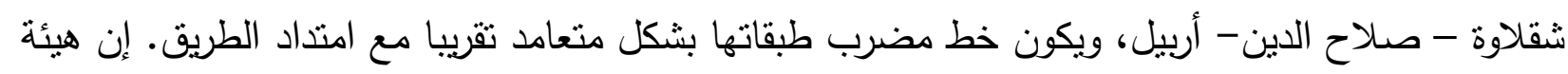
المكثف الصخري المحاذي للطريق يؤدي إلى حصول التساقط الصخري (Rock fall) لاسيما وإن صخور

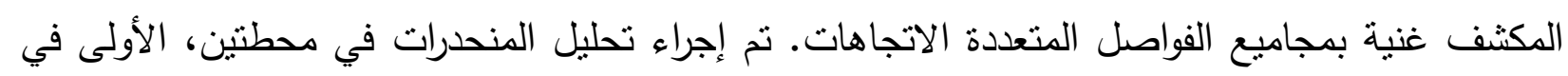
المحطة (6) من جهة منحدر الميل (Dip Slope) للحاجز، والثانية في المحطة (7) في جانب المنحدر الخلفي (Back Slope) للحاجز • وفيما يأتي وصف تحليل المنحدرات في هاتين المحطنين:

محطة رقم (6):

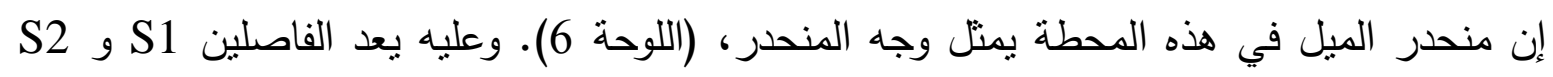
سطحي انزلاق مستوي، فيما يعمل الفاصل S3 كسطح انطلاق خلفي، (الثكل 7) النهل 


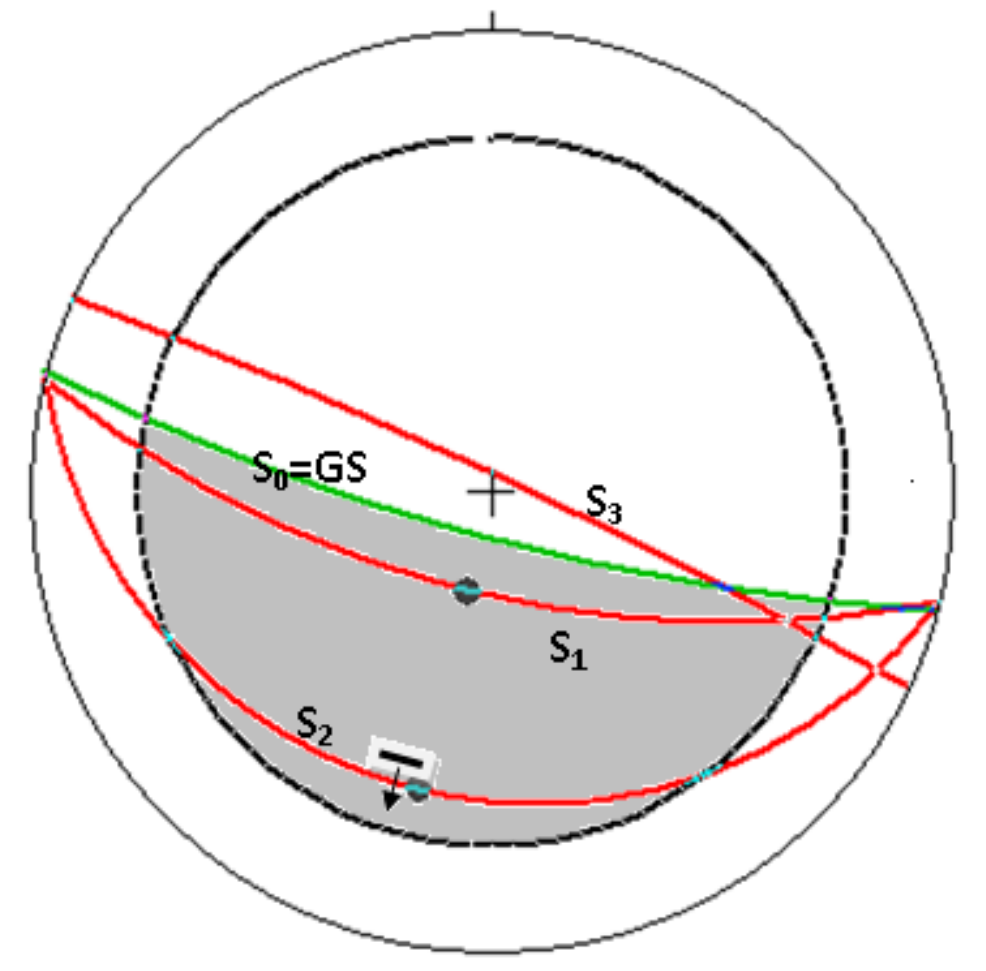

الثكل 7: المخطط الستيريوغرافي للمحطة (6) في تكوين خورمالة المتكون من حجر جيري مارلي، يبين الانزلاق المستوي الحاصل على مستوبي الفاصلين S1 و S2، فيما يعمل الفاصل S3 كسطح تحرر خلفي.

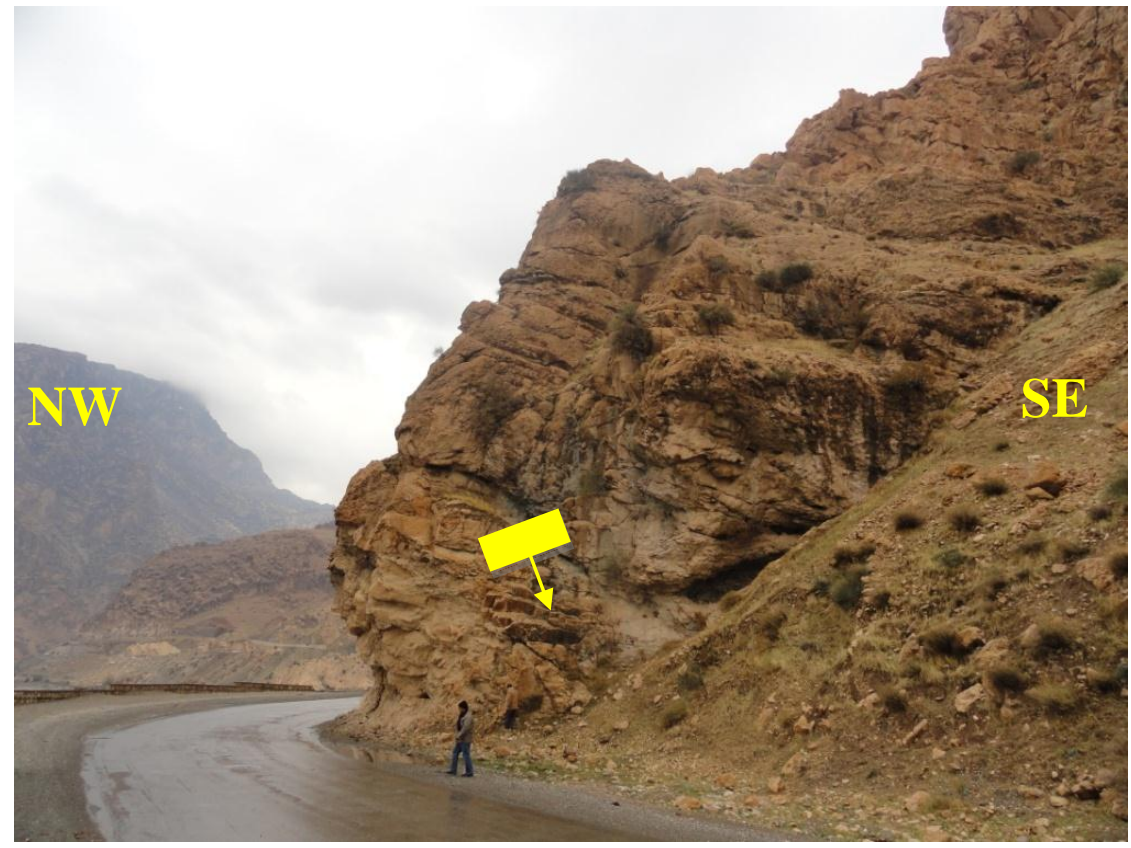

اللوحة 6: الانزلاق المستوي على أسطح الفواصل المضربية (hol) في طبقة الحجر الجيري المارلي في جانب منحدر الميل لحاجز تكوين خورمالة، محطة (6). 
محطة رقم (7):

إن احتمالية الانزلاق في هذه المحطة تحصل للإسفينين الصخربين بين سطح التطبق ومستوبي

الفاصلين S1. S2 على امتداد خط تقاطعهما مع سطح التطبق (الثكل 8، اللوحة 7).

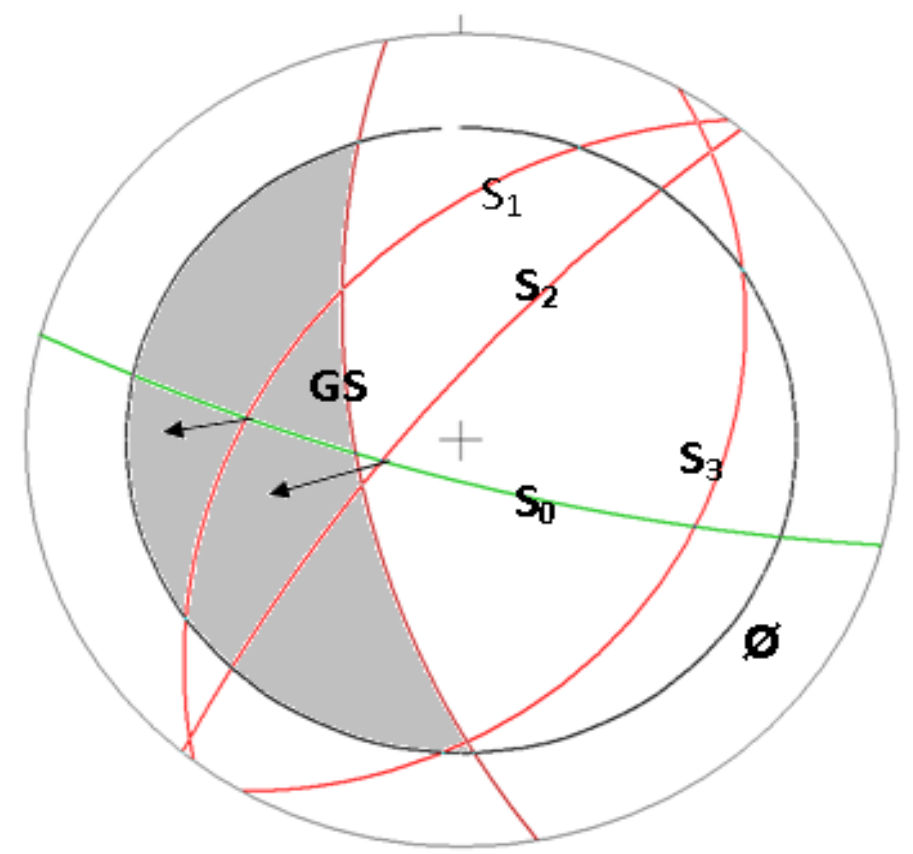

الثكل 8: المخطط الستيريوغرافي للمحطة (7) يبين العلاقة بين وجه المنحدر والانقطاعات المختلفة والانزلاق الإسفيني بين مستوى التطبق وكل من الفاصلين S1 و في تكوين خورمالة المتكون من حجر جيري مارلي.

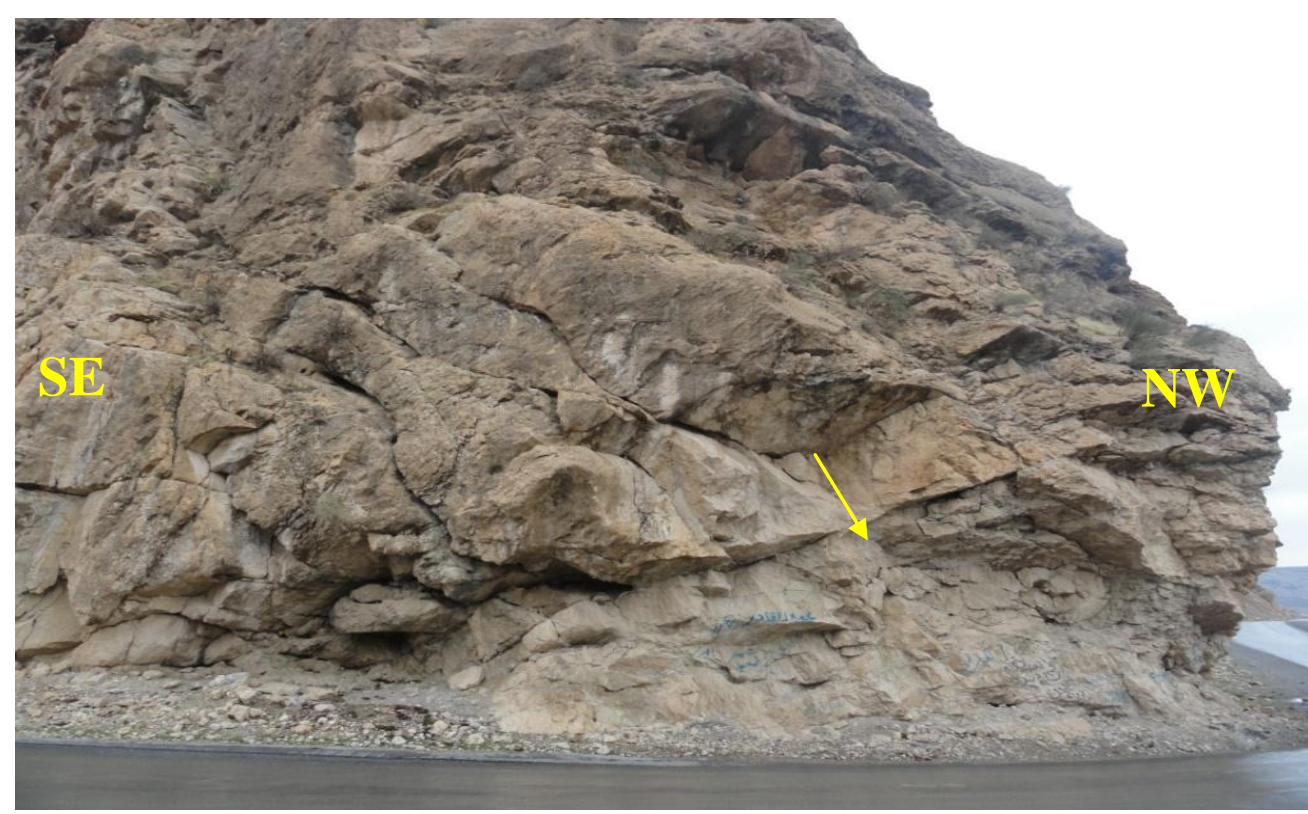

اللوحة 7: الانزلاق الإسفيني (المؤشر بسهم) بين مستوى التطبق والفواصل S1 وS2 في طبقة الحجر الجيري المارلي في جانب المنحدر الخلفي لحاجز تكوين خورمالة، محطة (7). 


\section{5- المنحدرات الصخرية لتكويني جركس وبيلاسبي:}

تتداخل صخور نكوين جركس الهشة مع طبقات تكوين بيلاسبي الجيرية المتلمتة وتشكل حواجز

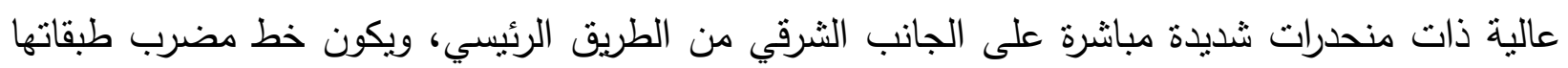

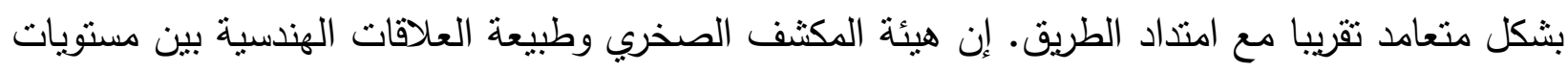
الانقطاعات فيها لا نظهر وجود إنزلاقات صخرية مستوية أو إسفينية فيها (شكل 9 9). ولكن ذللك يؤدي إلى

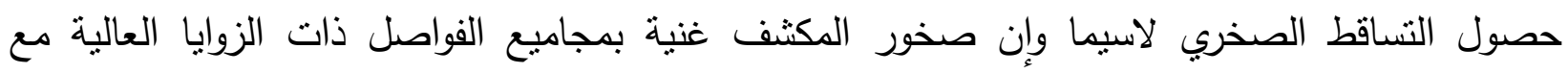
مستويات التطبق (لوحة 8). هذا فضلا عن أن طبقات صخور تكوين جركس المنداخلة مع تكوين بيلاسبي لأني

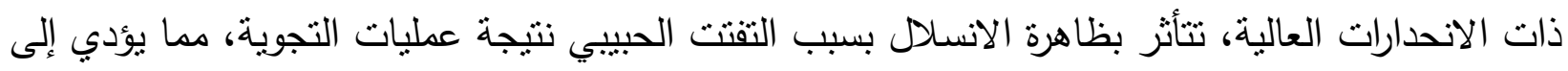
تراكها أسفل المنحدر وتتجاوز أحيانا كتق الطريق ونسبب مخاطر لسالكي الطريق.

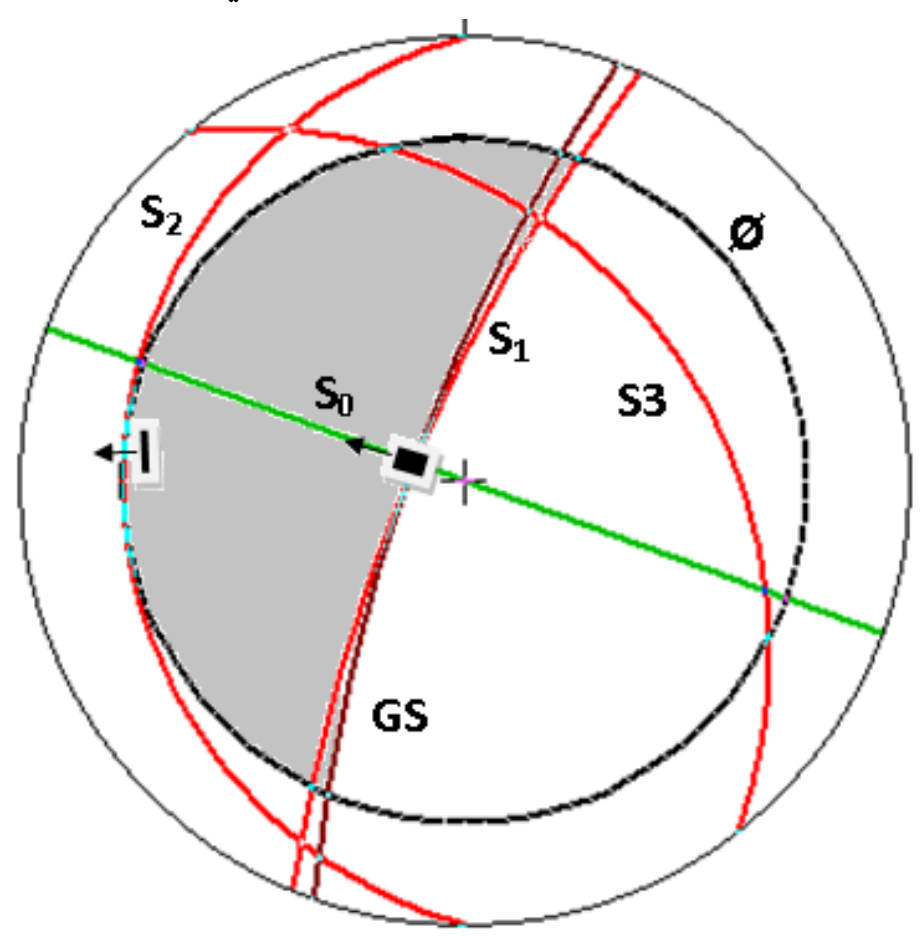

الثنكل 9: المخطط الستيريوغرافي للمحطة (5) يبين العلاقة بين وجه المنحدر والانقطاعات المختلفة لتكوين

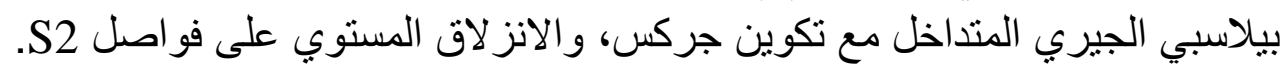




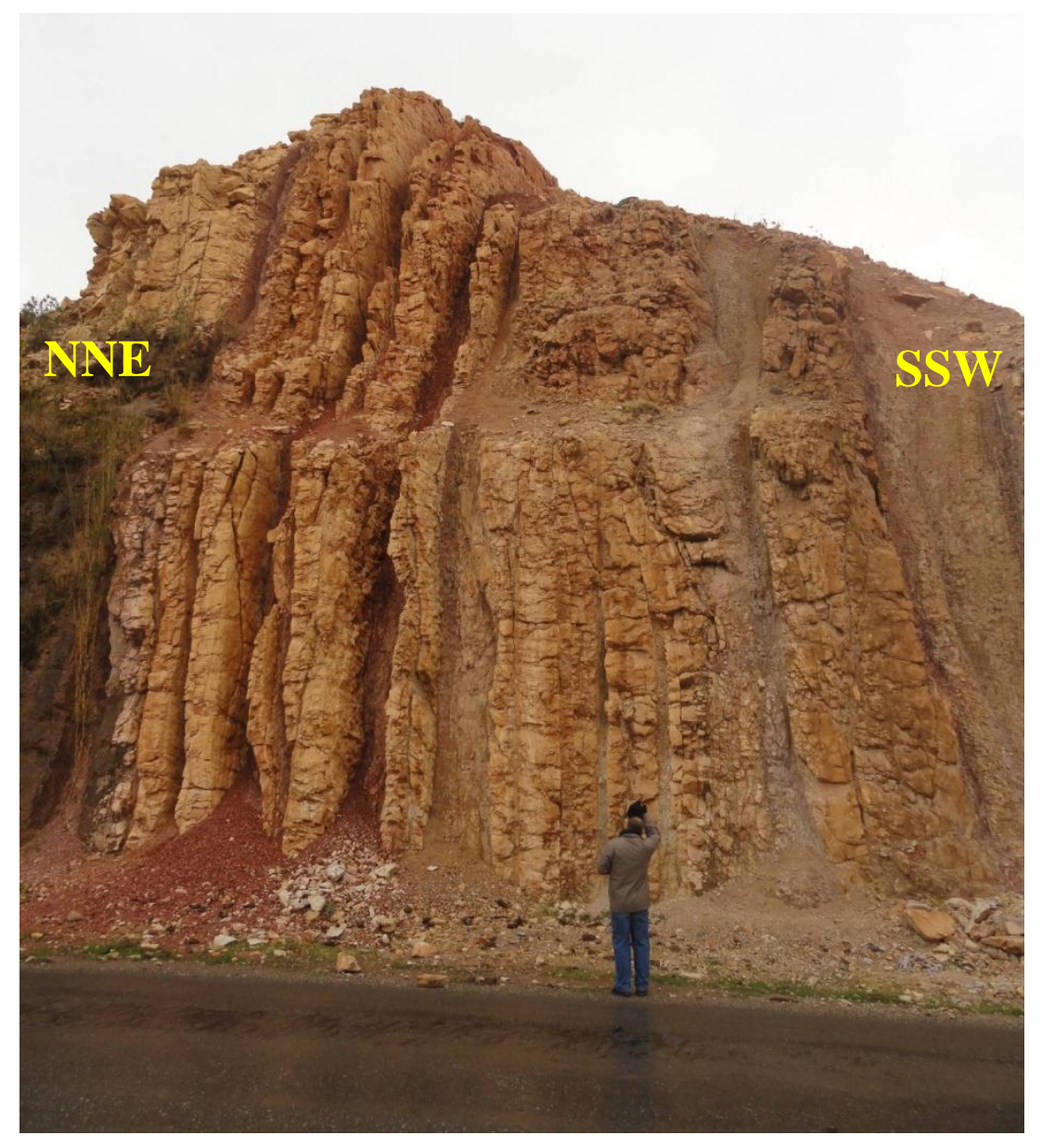

اللوحة 8: التساقط الصخري لقطع من طبقات حاجز تكوين بيلاسبي الجيري المتعامد مع امتداد الطريق، وانسلال فتاتيات طبقات تكوين جركس المنداخلة مع تكوين بيلاسبي في المحطة (5).

\section{المناقثة}

تلعب سطوح الانقطاع في الصخور المختلفة دورا فعالا يتحكم بنوعية حركات الانهيال الصخرية

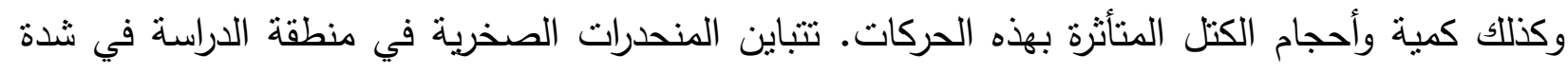

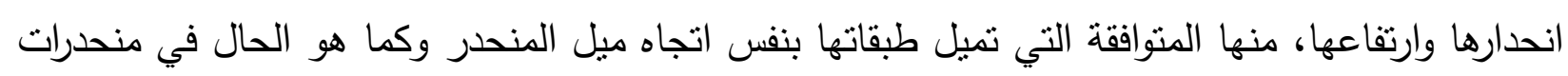

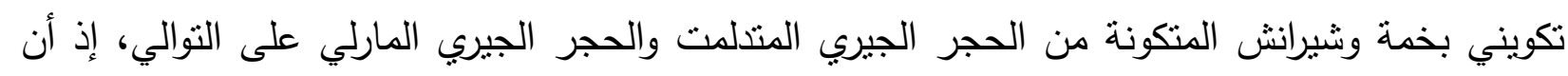

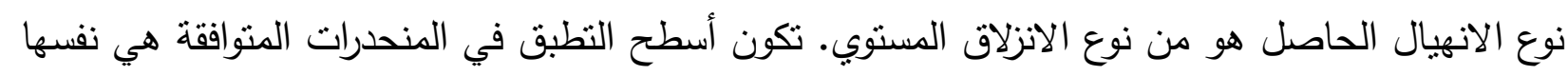

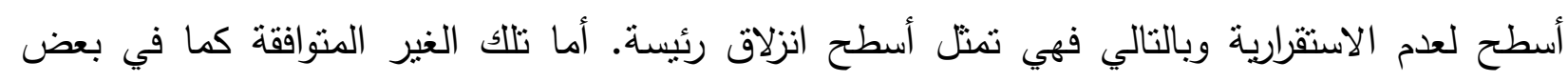

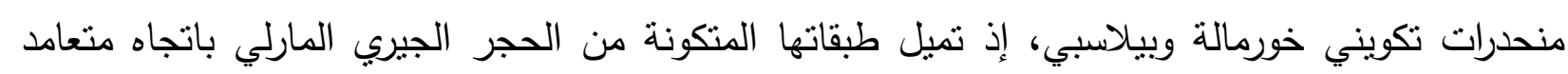

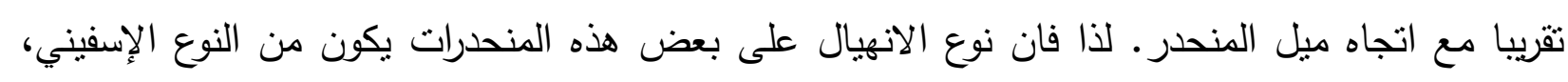


والبعض منها لا يحصل فيها أي من نوعي الانزلاق بسبب عدم ملائمة وضعية أسطح الانقطاع فيها. ولكنها تتأثز بالتساقط الصخري.

أما التكاوين المنكونة من الصخور الرخوة والهشة والتي تثمل تكويني تانجيرو (حجر رملي، طين،

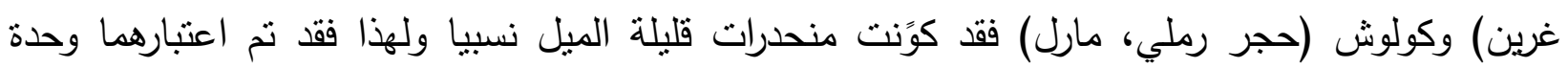
هندسية واحدة فيما يتعلق بحصول الانهيال، وكذلك الحال مع تكوين جركس، المتمثل بصخور الحجر

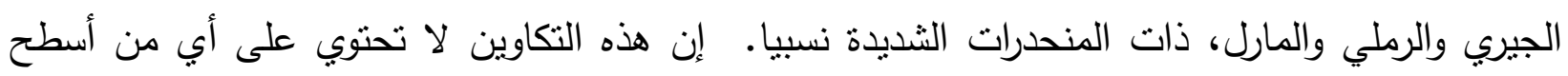
الانقطاع الصخري وبالنالي لا تتعرض لأي نوع من الانزلاق، بل أنها تعاني فقط من عملية الانسال والته والتفتت الصخري بفعل عوامل عديدة أهمها التجوية الصخرية.

\section{الاستتتاجات}

1- إن معظم المنحدرات الصخرية لمحطات منطقة الدراسة هي بنفس اتجاه ميل الطبقات وبزوايا ميل أكبر

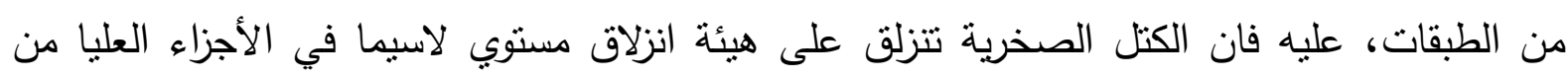

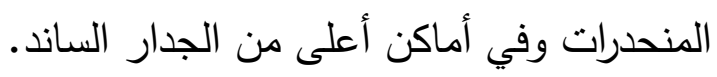

2- إن المنحدرات الصخرية لتكاوين تانجيرو وكولوش وجركس الهئة (حجر رملي، طين،مارل) تكون منأثرة

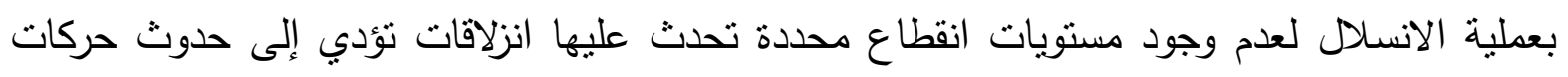
الانهيال، وكذللك التطبق الرقيق في تكوين جركس (حجر جيري، حجر رملي، مارل) المتداخل مع تكوين بيلاسبي (حجر جيري ومارل)، فضلا عن مقاومتها القليلة للتجوية فقد كونت منحدرات واطئة الميلان.

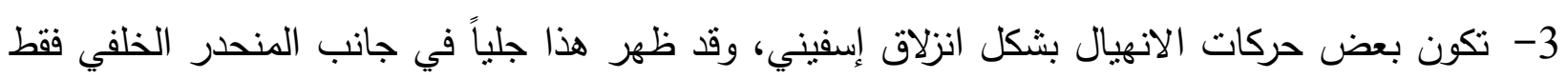

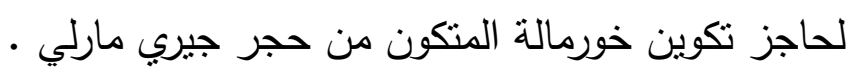

\section{المصادر العربية}

الحمداني، ربيع خلف حسن، 1991. طباقية وتركيبية الجزء الجنوبي الثرقي لطية بيرات المحدبة (منطقة بخمة ). أطروحة ماجستير غير منشورة، كلية العلوم، جامعة الموصل. 


\section{المصادر الاجنبية}

Al-jawadi, A. S. H., 2013. Evaluation of the Rock Mass at the Bekhme Dam Site, North East Iraq. Unpub. PhD Thesis College of Science, University of Mosul.183P.

Carson, M. A. and Kirkby, M. J.,1972. Hillside Form and Processes, Cambridge University Press, U.K.

Jassim, S. Z and Goff, T., 2006. Geology of Iraq. Published by Dolin, Prague and Moravian Museum, Brno, 341p.

Maerz, N., H., 2000. Highway Rock Cut Stability Assessment in Rock Masses Not Conductive to Stability Calculation. $51^{\text {st }}$ Annual Highway Geology Symposium, Washington. pp. 249 - 259.

Markland, J. T., 1972. A useful technique for estimating the stability of rock slopes when the rigid wedge sliding type of failure is expected. Imperial college rock mechanics research, report No. 19, 10p.

Omar, A, A,2005. An integrated structural and tectonic study of the Bina BawiSafin - Bradost region in Iraqi Kurdistan. Unpub. PhD Thesis, Sallahdeen University. 